appears that work on these lines has proceeded independently in other laboratories. Our experiments in this field began in 1946 and were described in the Annual Report of this Laboratory for $1947^{8}$ and in subsequent communications ${ }^{2}$.

We did not overlook Mr. Lederer's 1948 paper $^{9}$; but it was not referred to individually in our previous letters as it dealt with aqueous solutions. For the same reason we did not detail all the earlier work with aqueous solutions, but confined ourselves to the remarkable improvements which are possible when organic solvents are used under the best conditions.

R. P. Linstead

Chemical Research Laboratory, Teddington.

${ }^{1}$ Nature, 163, 292 (1949).

Nature, 1:2, 691 (1948); 163, 64 (1949).

'Nature, 163, 235 (1949).

"Goppelsroeder, F., "Kapillåranalyse"' (Dresden, 1910).

'Trey, H., $Z$. anal. Chem., 37, 743 (1898).

- Schwab, G. M., and Jockers, K., Naturwiss., 25, 44 (1937). 'Gordon, A. H., Martin, A. J. P., and Synge, R. L. M., Biochem. J.,

' Report of the Chemistry Research Board, 1947 (H.M. Stationery Office).

- Analytica Chimica Acta, 2, 261 (1948).

\section{Mechanism of Nitration of the Aromatic Nucleus}

IN order to check the constitution of preparations of the three different tritium toluenes carrying radiochemical amounts of tritium in the aromatic nucleus, samples were transformed into 2,4-dinitrotoluene with an excess of a mixture of 1 part (by volume) of con. centrated nitric acid and 2 parts of concentrated sulphuric acid. An experiment in which inactive toluene was nitrated with a rather strongly active mixture of acids showed that no hydrogen exchange takes place under the conditions of the reaction. No activity could be detected in the dinitrotoluene, though it had been possible to record an acquired tritium : protium ratio as small as 1 per cent of that of the surrounding mixture of acids and water, even if only one of the organic hydrogen atoms had taken part in the exchange.

It was to be supposed that on dinitration toluene-4-t would lose all, and toluene-3-t none, of its activity. Toluene-2-t, finally, would lose an amount corresponding to the relative velocities of nitration in the two ortho positions, carrying tritium and protium, respectively.

The different organic molecules were burnt and the specific activities of the water samples determined $^{1}$. In the calculation of the percentage of tritium remaining in the molecule after nitration, the different hydrogen contents of toluene and its dinitro derivative were taken inio account. The accompany. ing table gives the results.

In the case of toluene-4-t some other isomer seems to have been present in the sample.

In the case of toluene-2-t, both experimental figures equal 50 per cent just within the experi-

\begin{tabular}{|c|c|c|}
\hline \multirow{2}{*}{ Substance nitrated } & $\begin{array}{c}\text { Percentage of original tritium still present } \\
\text { in the 2,4-dinitrotoluene }\end{array}$ \\
\cline { 2 - 3 } & Theoretical & Observed \\
\hline $\begin{array}{c}\text { Toluene-4-t } \\
\text { Toluene-3-t } \\
\text { Toluene-2-t }\end{array}$ & $\begin{array}{c}100 \text { per cent } \\
(50)^{*}\end{array}$ & $\begin{array}{c}2 \cdot 2 \text { per cent } \\
99 \cdot 0\end{array}$ \\
$51 \cdot 9 ; 49 \cdot 7$ (two exp.) \\
\hline
\end{tabular}

- On the assumption of equal nitration velocity in tritium and protium positions. mental error, which implies that the nitration proceeds with very nearly the same velocity irrespective of whether tritium or protium originally occupies the position. In view of the great difference in mass (and therefore in the zero point energy of the original bond, the difference in which, however, may be more or less counterbalanced by a similar difference of the same magnitude in the 'activated complex' of the reaction, particularly if a base enters the complex ${ }^{2}$, it seems natural to suppose that the velocities should be different if the splitting off of the hydrogen takes part in the rate-determining step of the attack on the nucleus (which is not necessarily that of the reaction as a whole). Since there is no exchange of hydrogen with the acids and the water, the reason cannot be the existence of a dissociation equilibrium. The simplest way of accounting for the present observation seems to be the assumption of an addition of the nitrating agent $\left(\mathrm{NO}_{2}{ }^{+}\right)^{3,4}$ as the rate-determining step, followed by a rapid splitting-off of the hydrogen. The intermediate ion might have a quinonoid character.

\section{Nobel Institute for Physics,}

LARS MeLANDER

Stockholm 50. Oct. 25.

1 Melander, L., Acta Chem. Scand., 2 (in the press).

${ }^{2}$ Bennett, G. M., Brand, J. C. D., James, D. M., Saunders, T. G. and Williams, G., J. Chem. Soc., 474 (1947).

${ }^{3}$ Bennett, G. M., et al., several papers in J. Chem. Soc., 1946 and 1947.

' Ingold, C. K., et al., several communications in Nature, 158 (1946).

\section{Kinetics and Mechanism of Aromatic Nitration}

IN an earlier note ${ }^{1}$ it was shown how the study of the kinetics of nitration, particularly the study of reaction order, established $(a)$ the formation of the nitronium ion, and $(b)$ its effectiveness as the entity which attacks the aromatic molecule. Further kinetic investigation, particularly of salt and solvent effects, has given information on two other general features of the reaction. They relate to $(c)$ the reaction stages by which the nitronium ion is formed, and $(d)$ those by which it becomes a nitro-group in the aromatic compound.

(c) The stages by which the nitronium ion is formed may be discovered by reference mainly to conditions in which the rate of nitration is equal to the rate of formation of the nitronium ion. For the formation of nitronium ion from nitric acid, the stages are as follows :

$$
\begin{array}{cc}
\left.2 \mathrm{HNO}_{3} \underset{(2)}{\stackrel{(1)}{\rightleftharpoons}} \mathrm{H}_{2} \mathrm{NO}_{3}^{+}+\mathrm{NO}_{3}^{-} \quad \text { (1 and } 2 \text { fast }\right) \\
\mathrm{O}_{2} \mathrm{~N} . \stackrel{\mathrm{OH}_{2}}{\underset{(3)}{+}} \mathrm{O}_{2} \mathrm{~N}^{+}+\mathrm{OH}_{2} & \text { (3 slow })
\end{array}
$$

The proof of this rests on a hyperbolic repression by nitrate ions of the rate of nitration $\left(v \propto c^{-1}\right)$, without disturbance to the reaction order, even when it is of zero order. Other sufficiently strong acids, such as sulphuric acid, may replace one molecule of nitric acid in providing the proton required for the forma. tion of the nitric acidium ion, as illustrated in (1).

(d) The stages by which the nitronium ion enters the aromatic ring are elucidated by reference mainly to conditions of nitration in which the nitronium ion is rapidly formed. The transformation of the nitronium ion into an aromatic nitro-group is a twostage bimolecular process, the proton-loss having no kinetic significance: 